\title{
С.В. Люминарская
}

\section{ТЕОРЕТИЧЕСКИЙ АСПЕКТ ПРАВОВОГО ОБЕСПЕЧЕНИЯ ПЕНСИОННЫХ РЕФОРМ В РОССИИ}

В статье представлен общий анализ правового обеспечения ряда ключевых изменений пенсионного законодательства, проводимых в Российской Федерации в период с начала 2002 года по настоящее время. Исследуются вопросы качества нормативно-правовых актов, регулирующих пенсионные отношения с позиций юридической техники. Выявлен ряд негативных тенденций и дефектов правового регулирования, обозначены проблемные аспекты, возникающие в процессе изменения пенсионного законодательства, затрудняющие доступность правовых актов и ставящие под сомнение презумпцию знания закона. Особое внимание обращено на правовое обеспечение последнего этапа пенсионной реформы, связанного с повышением пенсионного возраста с 1 января 2019 года. Дана критическая оценка ряду законодательных решений, вызывающих трудности в реализации гражданами своих пенсионных прав. Обосновывается необходимость повышения качества правового регулирования в пенсионной сфере, что невозможно без проведения систематизации пенсионного законодательства.

Ключевые слова: правовое обеспечение, изменение законодательства, пенсионные реформы, презумпция знания закона, юридическая техника, качество законодательства, стабильность правового регулирования.

DOI: $10.35634 / 2412-9593-2020-30-3-406-411$

Термин «реформа» прочно вошел в нашу жизнь. Со времен глобальных преобразований начала 1990-х гг. государство не прекращает попыток найти ответы на разнообразные социальноэкономические вызовы, а правовое регулирование в социальной сфере демонстрирует уникальную динамику. Пенсионные реформы как важная часть социальных реформ всегда вызывают большой общественный резонанс и находятся в центре внимания широкого круга исследователей. Анализ правового обеспечения данных реформ с позиций общей теории права позволяет акцентировать проблемные вопросы совершенствования механизма изменения всего социального законодательства.

Следует начать с того, что любая социальная реформа требует качественного правового оформления. При этом правовое обеспечение пенсионных реформ требует глубокой работы по внесению множества изменений в огромное количество законодательных и подзаконных актов не только на федеральном, но и на региональном уровнях. Согласно ч. 2 ст. 39 Конституции Российской Федерации, государственные пенсии и социальные пособия устанавливаются законом. Таким образом, говоря о правовом обеспечении пенсионных реформ, прежде всего необходимо говорить об изменении законодательства.

Изменение законодательства можно рассматривать как общеправовой институт, обладающий многими характерными чертами и особенностями проявления во всех без исключения отраслях российского права [3. С. 3]. При этом понятия «изменение» и «реформа» соотносятся как общее и частное. Р.Б. Головкин и Н.Н. Трофимова в качестве сущностного признака реформ выделяют их позитивную направленность, отмечая, что реформа имеет отношение к характеристике проявления какихлибо свойств и процессов вовне, в то время как изменение может быть как внутренним (не проявленным), так и внешним формальным [2. С. 169]. Юридическая реформа - это система планомерных эволюционных изменений как самого права, так и основанных на праве изменений общественного бытия, направленных на усовершенствование функционирования общественных институтов и отношений в целях улучшения жизнедеятельности общества в целом, социальных групп и отдельных индивидов [2. С. 172].

Право социального обеспечения находится в процессе непрекращающихся изменений, связанных с повышением размеров определенных выплат, внесением в нормативные акты множества различных технических поправок. Время от времени появляются новые виды социального обеспечения или трансформируются старые. Поэтому «реформой» обычно называют не рядовые, а значительные концептуальные изменения, переход к чему-то качественно новому, значительно отличающемуся от привычного. Так, обобщая опыт проведения пенсионных реформ в новейший период истории права социального обеспечения в России, условно можно выделить несколько ключевых этапов. 
Теоретический аспект правового обеспечения пенсионных реформ в России

Первый этап начался 1 января 2002 г. с вступлением в силу трех новых системообразующих федеральных законов: от 15.12.2001 № 166-Ф3 «О государственном пенсионном обеспечении в Российской Федерации», от 15.12.2001 № 167-Ф3 «Об обязательном пенсионном страховании в Российской Федерации» и от 17.12.2001 № 173-Ф3 «О трудовых пенсиях в Российской Федерации». При этом старый Закон РФ от 20.11.1990 № 340-1 «О государственных пенсиях в Российской Федерации» утратил силу.

На этом этапе произошла качественная трансформация привычной солидарно-распределительной системы пенсионного обеспечения. Изменились условия назначения пенсий - трудовое участие перестало играть значимую роль, и трудовой стаж оказался окончательно заменен страховым. Был внедрен совершенно новый алгоритм исчисления пенсий. Произошла имплементация частноправовых конструкций в публично-правовой механизм обязательного пенсионного страхования, положено начало формированию пенсионных накоплений.

Пенсионная реформа 2002 г. вызвала большую волну критики. Следует согласиться, что негативный опыт этого этапа реформирования еще долгое время будет выступать объектом разнообразных исследований [4. С. 215].

Второй этап значимых законодательных изменений в рассматриваемой сфере был реализован с 1 января 2010 г. ${ }^{1}$ Его обычно не называют реформой, однако он был связан с рядом важных для пенсионной системы преобразований, в частности, с отказом от единого социального налога в пользу страховых взносов в Пенсионный фонд РФ, Фонд социального страхования РФ, Федеральный фонд обязательного медицинского страхования с одновременным установлением предельной взносооблагаемой базы, косвенно ограничивающей размер трудовой пенсии.

Кроме того, были изменены условия назначения пенсий по инвалидности - степени ограничения способности к труду заменены более справедливым условием о группах инвалидности. Алгоритм исчисления размеров трудовых пенсий был дополнен правилами о валоризации. Базовая часть трудовой пенсии (БЧ) получила новое название «фиксированный базовый размер» (Б) и стала финансироваться за счет страховых взносов (солидарной части тарифа), а не из бюджета РФ. Также появился новый вид государственной социальной помощи - социальная доплата к пенсии, что гарантировало доведение общей суммы материального обеспечения пенсионера до величины прожиточного минимума пенсионера (устанавливаемого в субъекте Российской Федерации один раз в год, в соответствии с п. 4 ст. 4 Федерального закона от 24.10.1997 № 134-Ф3 «О прожиточном минимуме в Российской Федерации»).

В продолжение данного этапа с 1 января 2013 г. были введены дополнительные страховые взносы в Пенсионный фонд РФ $\Phi^{2}$ как одно из условий досрочного назначения трудовой пенсии по старости $^{3}$. Данные страховые взносы подлежали уплате, если класс условий труда на рабочих местах по определенным видам работ соответствовал вредному и (или) опасному классу, установленному по результатам специальной оценки условий труда, что обострило проблему отказов в назначении досрочных пенсий из-за недобросовестности работодателей.

Третий этап реформирования в рассматриваемой сфере был связан с вступлением в силу с 1 января 2015 г. Федерального закона от 28.12.2013 № 400-Ф3 «О страховых пенсиях» - трудовые пенсии были заменены страховыми. Значительно изменились условия назначения страховых пенсий (были повышены требования к страховому стажу, введен индивидуальный пенсионный коэффициент). Снова кардинально был пересмотрен алгоритм исчисления размеров пенсий. При этом накопительная часть трудовых пенсий по старости трансформировалась в самостоятельный тип пенсий и нашла закрепление в нормах нового Федерального закона от 28.12.2013 № 424-Ф3 «О накопительной пенсии».

\footnotetext{
${ }^{1}$ См.: Федеральный закон от 24.07.2009 № 213-Ф3 «О внесении изменений в отдельные законодательные акты Российской Федерации и признании утратившими силу отдельных законодательных актов (положений законодательных актов) Российской Федерации в связи с принятием Федерального закона "О страховых взносах в Пенсионный фонд Российской Федерации, Фонд социального страхования Российской Федерации, Федеральный фонд обязательного медицинского страхования и территориальные фонды обязательного медицинского страхования"».

${ }^{2}$ Статья 58.3 Федерального закона от 24 июля 2009 года № 212-Ф3 «О страховых взносах в Пенсионный фонд Российской Федерации, Фонд социального страхования Российской Федерации, Федеральный фонд обязательного медицинского страхования».

${ }^{3}$ Часть 3 ст. 27 Федерального закона от 17.12.2001 № 173-Ф3 «О трудовых пенсиях в Российской Федерации».
} 
Последний этап реформирования пенсионного обеспечения связывают с повышением пенсионного возраста с 1 января 2019 г. ${ }^{4}$

Рассматривая вопросы правовой регламентации перечисленных пенсионных реформ, особенно во взаимосвязи с другими правовыми преобразованиями в смежных сферах - налоговом, административном, трудовом праве, можно обнаружить ряд проблем.

Самой очевидной из них является устойчивая тенденция к увеличению количества законодательных актов с одновременным усложнением правообразующих составов, определяющих право на пенсии (пенсионных оснований). От этапа к этапу происходит увеличение объема законов, растет количество отсылочных норм, происходит утяжеление правовых конструкций. Одни и те же термины используются в разном смысловом значении (например, законодатель неоднократно менял содержание понятий «корректировка» и «перерасчет»). Алгоритмы исчисления размеров пенсий перегружены и предельно сложны. Сложен и несовершенен понятийный аппарат. В качестве иллюстрации здесь достаточно привести определение одного из элементов пенсионной формулы - «КвСП», который используется при исчислении размера страховой пенсии по старости или страховой пенсии по случаю потери кормильца. Согласно ч. 9 ст. 15 Федерального закона от 28.12.2013 № 400-ФЗ, КвСП это «коэффициент повышения индивидуального пенсионного коэффициента».

Как известно, одним из условий применения правовых актов является их публичная доступность. С позиции юридической техники доступность обеспечивается такими средствами, как использование максимально простых терминов, фраз, широко употребляемых в обычном обиходе и легко воспринимаемых большей частью населения; отказ от использования в правовых актах сложных конструкций с причастными и деепричастными оборотами; отказ от злоупотребления иностранными словами; отказ от использования некоторых канцелярских оборотов, бюрократических штампов, архаичных выражений и т. д. [5. С. 26]. К сожалению, в правовом регулировании пенсионных отношений зачастую все происходит наоборот.

Формально, правовые акты доступны в том смысле, что они подлежат обязательному опубликованию. Также в последние годы создано немало информационных ресурсов и сервисов, концентрирующих информацию о происходящих в пенсионной сфере изменениях. Следует положительно оценить принятие дополнительных просветительских мер, однако все это не гарантирует правильного усвоения смысла правовых норм. Презумпцию знания закона подрывает ситуация, при которой обычный гражданин не в состоянии уяснить смысл изучаемого закона путем обыденного толкования, не прибегая к помощи юриста-профессионала [1. С. 17].

Абсолютное большинство социально-обеспечительных правоотношений возникает в заявительном порядке, незнание, непонимание гражданами своих прав означает невозможность их реализации. Учитывая, что адресатами правовых норм в праве социального обеспечения выступают нуждающиеся лица, которые в силу возраста, состояния здоровья, сложной жизненной ситуации зачастую испытывают сложности с реализацией своих прав, государству необходимо обеспечить все условия для того, чтобы эти граждане получили верное представление о своем юридическом статусе.

В качестве примера неудачных решений можно привести последние изменения норм о пенсионном возрасте.

Так, с 1 января 2019 года ч. 1 ст. 8 Федерального закона от 28.12.2013 № 400-ФЗ действует в новой редакции, согласно которой право на страховую пенсию по старости получают лица, достигшие возраста 65 и 60 лет (соответственно, мужчины и женщины) с учетом положений, предусмотренных приложением 6. В указанном приложении закреплены правила поэтапного повышения пенсионного возраста для лиц, которые ожидали назначения страховой пенсии в 2019 - 2023 гг. Например, для граждан, ожидавших выйти на пенсию в 2019 году, возрастная планка повышена на 12 месяцев. Для лиц, ожидавших выйти на пенсию в 2020 г., требования к возрасту увеличены на 24 месяца.

Однако в законодательстве имеется дополнительная оговорка, согласно которой названным лицам страховая пенсия по старости может назначаться ранее достижения возраста, предусмотренного приложением 6, но не более чем за 6 месяцев до достижения такого возраста. Это правило (по сути льготное условие пенсионного обеспечения) не попало в текст Федерального закона от 28.12.2013 № 400-Ф3, а осталось «скрыто» в тексте поправочного закона 5 .

\footnotetext{
${ }^{4}$ См.: Федеральный закон от 03.10.2018 № 350-Ф3 «О внесении изменений в отдельные законодательные акты Российской Федерации по вопросам назначения и выплаты пенсий».

5 Часть 3 ст. 10 Федерального закона от 03.10.2018 № 350-Ф3 «О внесении изменений в отдельные законодательные акты Российской Федерации по вопросам назначения и выплаты пенсий».
} 
Формулировку «может назначаться» здесь не следует воспринимать как лазейку для принятия территориальными органами Пенсионного фонда РФ усмотренческих решений о праве на пенсию, граждане имеют право требовать назначения пенсии за 6 месяцев до достижения соответствующего возраста. Единственное препятствие этому - незнание закона.

Еще одной важной гарантией правовой осведомленности граждан служит стабильность правового регулирования. Конституционный Суд РФ давно и неоднократно указывал на необходимость поддержания доверия граждан к закону и действиям государства, необходимость сохранения правовой определенности, разумной стабильности правового регулирования, недопустимости внесения произвольных изменений в действующую систему норм, обеспечение предсказуемости законодательной политики в социальной сфере 6 .

Согласно п. 57 Методических рекомендаций по юридико-техническому оформлению законопроектов, изменения всегда должны вноситься только в основной законодательный акт. Вносить изменения в основной законодательный акт путем внесения изменений в изменяющий его законодательный акт недопустимо. Однако в рассматриваемой сфере такие примеры встречаются. Так, Федеральный закон от 24.07.2009 № 213-Ф3 «О внесении изменений в отдельные законодательные акты Российской Федерации и признании утратившими силу отдельных законодательных актов (положений законодательных актов) Российской Федерации в связи с принятием Федерального закона "О страховых взносах в Пенсионный фонд Российской Федерации, Фонд социального страхования Российской Федерации, Федеральный фонд обязательного медицинского страхования и территориальные фонды обязательного медицинского страхования"》 с момента начала действия изменялся неоднократно.

Еще одной из проблем, осложняющих понимание смысла правовых норм, служит практика приостановления действия отдельных статей пенсионных законов и ее правовое оформление. Например, с 1 января 2019 г. приостановлено действие ряда положений ст. 15 Федерального закона от 28.12.2013 № 400-Ф3, касающихся ключевого элемента алгоритма расчета размеров страховых пенсий. Лица, желающие определить размер собственной пенсии, должны приложить дополнительные усилия к поиску ответа на вопрос о стоимости пенсионного коэффициента. Для этого им необходимо обратиться к нормам поправочного закона ${ }^{7}$, где указана эта стоимость на период с 2019 до 2024 г.

Сложнее дело обстоит с определением размера фиксированной выплаты к страховой пенсии. Статья 16 Федерального закона от 28.12.2013 № 400-Ф3 говорит, что соответствующий размер равен 4982 руб. 90 коп. в месяц. Однако нормами другого закона ${ }^{8}$ установлены иные размеры (с 1 января 2020 г. - 5686 руб. 25 коп. в месяц).

Подобного рода трудности ждут и тех, кто хочет разобраться в методике определения размеров пенсий для лиц, проходивших военную службу по контракту. Действие норм, призванных помочь в определении размера денежного довольствия для исчисления пенсий ${ }^{9}$ с 1 января 2015 г., приостановлено. Для того чтобы определить размер этого денежного довольствия, требуется знать о существовании отдельных законов ${ }^{10}$, которые периодически (как правило, раз в год) обновляются.

\footnotetext{
${ }^{6}$ См.: Постановления Конституционного Суда РФ от 16.12.1997 № 20-П, от 24.05.2001 № 8-П, от 19.06.2002 № 11-П, от 23.04.2004 № 9-П, Определения Конституционного Суда РФ от 04.12.2003 № 415-О, от 15.02.2005 № 17-О, от 01.12.2005 3 521-О и др.

7 Часть 7 ст. 10 Федерального закона от 03.10.2018 № 350-Ф3 «О внесении изменений в отдельные законодательные акты Российской Федерации по вопросам назначения и выплаты пенсий».

${ }^{8}$ Часть 8 ст. 10 Федерального закона от 03.10.2018 № 350-Ф3 «О внесении изменений в отдельные законодательные акты Российской Федерации по вопросам назначения и выплаты пенсий».

9 Часть 2 ст. 43 Закона РФ от 12.02.1993 № 4468-1 «О пенсионном обеспечении лиц, проходивших военную службу, службу в органах внутренних дел, Государственной противопожарной службе, органах по контролю за оборотом наркотических средств и психотропных веществ, учреждениях и органах уголовно-исполнительной системы, войсках национальной гвардии Российской Федерации, органах принудительного исполнения Российской Федерации, и их семей».

${ }^{10}$ См.: Федеральный закон от 02.12.2019 № 381-Ф3 «О приостановлении действия части второй статьи 43 Закона Российской Федерации "О пенсионном обеспечении лиц, проходивших военную службу, службу в органах внутренних дел, Государственной противопожарной службе, органах по контролю за оборотом наркотических средств и психотропных веществ, учреждениях и органах уголовно-исполнительной системы, войсках национальной гвардии Российской Федерации, органах принудительного исполнения Российской Федерации, и их семей”» в связи с Федеральным законом "О федеральном бюджете на 2020 год и на плановый период 2021 и 2022 годов"».
} 
Продолжая анализировать динамику изменений пенсионного законодательства, хотелось бы обратить внимание на еще один, на наш взгляд, значимый момент. С позиций юридической техники в числе формальных требований, предъявляемых к нормативным актам, называют требования к реквизитам. Одним из реквизитов выступает заголовок - наименование нормативного акта, цель которого лаконично отразить основную идею нормативного акта, его тематику. При этом важны точность, краткость, оптимальная обобщенность содержания нормативного акта, емкость и формализованность [5. C. 36].

Так, например, заголовок Закона РФ от 12.02.1993 № 4468-1 «О пенсионном обеспечении лиц, проходивших военную службу, службу в органах внутренних дел, Государственной противопожарной службе, органах по контролю за оборотом наркотических средств и психотропных веществ, учреждениях и органах уголовно-исполнительной системы, войсках национальной гвардии Российской Федерации, органах принудительного исполнения Российской Федерации, и их семей» с 1 января 2020 г. был в очередной (шестой) раз изменен.

Представляется необходимым сформулировать наименование данного закона более лаконичным образом, так, чтобы его не требовалось менять всякий раз, когда происходит реформирование соответствующих властных структур. Излишне напоминать, что изменение наименования закона всегда влечет необходимость внесения правок в огромное количество иных нормативных актов самого различного уровня и отраслевой принадлежности.

Многие авторы отмечают поспешность и непоследовательность проведения пенсионных реформ. Зачастую те нормативно-правовые акты, которые были призваны создать механизм реализации новых пенсионных законов, принимаются с опозданием. Например, ожидаемый период выплаты трудовой пенсии по старости для расчета накопительной части трудовой пенсии был установлен лишь в 2009 г., хотя к тому моменту граждане уже могли приобрести право на такую выплату. Отдельные законодательные акты, предусмотренные еще на первом этапе реформирования, до сих пор отсутствуют.

В то же время имеются примеры относительно новых норм, которые ждали своего часа, но так и не успели заработать. Например, ч.17 ст. 14 Федерального закона от 17.12.2001 № 173-Ф3 «О трудовых пенсиях в Российской Федерации» должна была связать фиксированный базовый размер страховой части трудовой пенсии по старости с продолжительностью страхового стажа. По общему правилу, данную выплату предполагалось увеличивать на 6\% за каждый полный год страхового стажа, превышающего 30 лет для мужчин и 25 лет для женщин. Данные нормы должны были вступить в силу с 1 января 2015 г., однако в тот день на смену Федеральному закону от 17.12.2001 № 173-ФЗ пришел новый Федеральный закон от 28.12.2013 № 400-Ф3, и подобное правило в нем отсутствует.

Пенсионные отношения имеют длящийся характер, им предшествует длительный этап формирования пенсионных ожиданий, поэтому каждый новый этап реформирования требует усилий по сохранению пенсионных прав. Это обусловливает ультраактивность (переживание) пенсионных норм. Проиллюстрировать это можно на примере действия Федерального закона от 17.12.2001 № 173-Ф3 «О трудовых пенсиях в Российской Федерации».

Как уже было отмечено, с 1 января 2015 г. данный закон фактически утратил силу. Однако во исполнение ряда положений ст. 15 Федерального закона от 28.12.2013 № 400-Ф3 он продолжает применяться в целях исчисления размеров страховых пенсий. Интересно, что в этот фактически не работающий закон продолжают вноситься изменения.

Подводя итоги, следует еще раз отметить, что, принимая решение о необходимости проведения любых преобразований в сфере пенсионного обеспечения, законодателю необходимо особо тщательно подходить к вопросам юридической техники. Требуется сосредоточить усилия на повышении качества пенсионного законодательства. В то же время успешная реализация такой цели вряд ли возможна в условиях недостаточной систематизации правовых актов, регулирующих пенсионные отношения. Поэтому первостепенной задачей законодателя в рассматриваемой сфере является упорядочение и приведение действующих правовых актов в единую согласованную систему.

\section{СПИСОК ЛИТЕРАТУРЫ}

1. Головина А.А. Дефекты законодательной техники как препятствие обыденному толкованию права // Журнал российского права. 2017. № 4 (244). С. 16-26.

2. Головкин Р.Б., Трофимова Н.Н. Понятие «юридическая реформа» // Вестник Владимирского юридического института. Владимир, 2014. С. 168-172. 
3. Гущев М.Е. Изменение законодательства России: проблемы теории и практики: автореф. дис. ... канд. юрид. наук / Нижегор. акад. МВД России. Н. Новгород, 2006. 32 c.

4. Маматказин И.Р. Страховая пенсия как показатель качества трудовой жизни // За права трудящихся! Повышение качества трудовой жизни как стратегическая задача государства и профсоюзов: материалы Пятой Междунар. науч.-практ. конф. (Екатеринбург, 18-19 дек. 2019 г.) / Урал. гос. юрид. ун-т, Профсоюз работников СЮИ-УрГЮА-УрГЮУ; под общ. ред. Н. А. Новиковой. Екатеринбург, 2019. С. 210-217.

5. Томин В.А. Юридическая техника: учеб.пособие. СПб.: Санкт-Петербургский юридический институт (филиал) Академии Генеральной прокуратуры Российской Федерации, 2015. 84 с.

Поступила в редакцию 22.04.2020

Люминарская Светлана Валерьевна, кандидат юридических наук, доцент кафедры экологического, природоресурсного и трудового права

ФГБОУ ВО «Удмуртский государственный университет»

426034, Россия, г. Ижевск, ул. Университетская, 1 (корп. 4)

E-mail: luminarskaja.s@yandex.ru

\section{S.V. Lyuminarskaya}

THE THEORETICAL ASPECT OF LEGAL SUPPORT OF PENSION REFORMS IN RUSSIA

DOI: $10.35634 / 2412-9593-2020-30-3-406-411$

The article provides a general analysis of the legal support for a number of key changes in the pension legislation that have been implemented in the Russian Federation since the beginning of 2002 to the present. The article examines the quality of legal acts regulating pension relations from the point of legal technology. A number of negative trends and defects in legal regulation have been identified, as well as problematic aspects arising in the process of changing pension legislation that make it difficult to access legal acts and call into question the presumption of knowledge of the law. Special attention is paid to the legal support of the last stage of the pension reform, related to the increase in the retirement age from January 1, 2019. A critical assessment is given to a number of legislative decisions that cause difficulties in the implementation of citizens' pension rights. The article substantiates the need to improve the quality of legal regulation in the pension sphere, which is impossible without systematization of pension legislation.

Keywords: legal support; changes in legislation; pension reforms; presumed knowledge of the law; legal technique; quality of legislation; stability of legal regulation.

Received 22.04.2020

Lyuminarskaya S.V., Candidate of Law, Associate Professor

at Department of environmental, natural resource and labor law Udmurt State University

Universitetskaya st., 1/4, Izhevsk, Russia, 426034

E-mail: luminarskaja.s@yandex.ru 